\title{
GOVERNANÇA EM COOPERATIVAS AGROPECUÁRIAS: UM ESTUDO SOB A ÓTICA DA ARQUITETURA CONTRATUAL
}

\author{
Bianca Bigolin Liszbinski ${ }^{1}$, Clea Beatriz Macagnan², Tiago Zardin Patias ${ }^{3}$, Francis \\ Diego Motke ${ }^{4}$, Oberdan Teles da Silva ${ }^{5}$
}

\section{RESUMO}

O objeto de estudo desta pesquisa são as práticas de governança em organizações cooperativas. A pesquisa busca identificar de que forma estão refletidas as ações de governança em cooperativas agropecuárias, por meio da análise de informações presentes nos estatutos sociais. O estudo caracteriza-se metodologicamente como sendo descritivo com evidências qualitativas, sendo que foram analisados doze estatutos de cooperativas agropecuárias. Para o seu desenvolvimento, primeiramente foram construídos indicadores a partir de pressupostos de governança citados por diferentes autores. Após, estes indicadores serviram de base para a comparação com as ações adotadas em cada cooperativa. A análise da amostra possibilitou inferir que as práticas que caracterizam a governança nas organizações cooperativas necessitam de ajustes e em outras a implantação das mesmas.

Palavras-chave: Cooperativas. Governança. Estatuto Social.

\section{GOVERNANCE IN AGRICULTURAL COOPERATIVE: A STUDY IN THE PERSPECTIVE OF CONTRACT ARCHITECTURE}

\begin{abstract}
The object of study of this research are governance practices in cooperative organizations. The research seeks to identify how the governance actions are reflected in agricultural cooperatives, through the analysis of information contained in the bylaws. The study is methodologically characterized as descriptive with qualitative evidence, and were analyzed twelve statutes of agricultural cooperatives. For its development, they were first constructed from indicators of governance assumptions cited by different authors. After these indicators served as a basis for comparison with the actions taken in each cooperative. The analysis of the sample made it possible to infer that the practices that characterize governance in cooperatives organizations require adjustments and other implementation of the same.
\end{abstract}

Keywords: Cooperatives. Governance. Social Statute.

\section{INTRODUÇÃO}

As organizações cooperativas agropecuárias desempenham papel importante no desenvolvimento econômico e social, formando um elo entre o mercado em que atuam e o setor que representam: pequenos e médios produtores rurais (FRANSI; SALLA; VIADIU, 2007). Esse tipo de organização objetiva prestar apoio aos seus associados na industrialização, na comercialização de seus produtos e em casos de necessidades financeiras. Oportunizam ganhos econômicos a seus associados por meio do gerenciamento de recursos de forma

\footnotetext{
${ }^{1}$ Universidade Federal de Santa Maria - UFSM, Campus de Palmeira das Missões

${ }^{2}$ Universidade do Vale do Rio dos Sinos - UNISINOS

${ }^{3}$ Universidade Federal do Pampa - UNIPAMPA, Campus Santana do Livramento

${ }^{4}$ Universidade Federal de Santa Maria - UFSM

${ }^{5}$ Universidade Estadual do Rio Grande do Sul - UERGS
} 
colaborativa que propiciam a superação de desafios que são impostos pelo mercado, alavancando assim o seu crescimento e proporcionando redução das desigualdades sociais (BIALOSKORSKI NETO, 2012).

As organizações cooperativas, ao longo da história, têm demonstrado grande capacidade de geração de bem-estar e riqueza para o mundo rural constituindo-se, em muitas ocasiões, o principal instrumento empresarial a serviço desta comunidade (MARTÍ; IGUAL, 2008). Como essas organizações estão voltadas especialmente ao atendimento das necessidades dos seus associados e estes têm interesse que os negócios funcionem segundo os objetivos que o levaram a esta associação (MARTÍNEZ, 2008), também o seu sistema diretivo estaria fundamentado na participação democrática destes indivíduos. Fundamentalmente, esta participação se dá pela eleição de representantes que deveriam atuar segundo o sistema de regramento estabelecido nos estatutos sociais desde a formação da respectiva organização cooperativa.

O fator relevante que instiga a reflexão sobre governança em cooperativas é que a gestão da mesma é estabelecida por uns poucos sócios (associados representantes eleitos em assembleia) ou por profissionais contratados que deteriam o controle sobre as decisões e o sistema de gestão, enquanto que a grande parte dos sócios deteria apenas a propriedade passiva (BERLE; MEANS, 1984). Este cenário oportunizaria a possibilidade de emergência de conflitos de interesse, uma vez que os administradores (sejam eles associados ou profissionais contratados) poderiam optar por decisões que privilegiassem seus interesses em detrimento da grande maioria dos associados. Dessa forma, o sistema de governança possibilitaria o estabelecimento de regras que minimizassem conflitos de interesse entre associados gestores e demais associados.

A partir desta contextualização buscou-se nesta pesquisa responder ao seguinte questionamento: de que forma estão refletidos os mecanismos de governança no ambiente cooperativo? O objetivo principal da pesquisa é a evidenciação da utilização de práticas de governança em cooperativas agropecuárias, a partir da análise de informações presentes nos estatutos sociais. O desenvolvimento desta pesquisa observando-se os pressupostos da arquitetura contratual justifica-se pelo fato de os estatutos sociais fundamentarem os pressupostos de governança dessas organizações, mesmo que implicitamente.

Ademais, a possibilidade de contribuição em termos de conhecimento sobre as práticas de governança nas organizações cooperativas revela-se proeminente pela necessidade constante de aprimoramento das formas de governo dessas organizações. Esta perspectiva de 
análise vem ao encontro das observações de Giarola et. al., (2007), os quais afirmam que os princípios e práticas de governança, um diferencial antes observado apenas em organizações de grande porte ou que tenham seu capital negociado no mercado aberto, passaram a ser um aspecto a ser considerado também nas cooperativas. A governança possibilita as cooperativas uma gestão mais estratégica, visto que a adoção de boas práticas de governança ocupa um espaço cada vez mais significativo no debate acerca da criação das condições necessárias para o desenvolvimento de um sistema diretivo eficiente das organizações (BORGEN, 2011).

\section{ORGANIZAÇÕES COOPERATIVAS}

De forma simplificada, as cooperativas são definidas como sociedades de pessoas, constituídas em bases democráticas e com características empresariais. As mesmas possuem legislação e finalidades específicas para a solução de problemas econômicos e sociais a todos associados, funcionários e comunidade (PEREIRA, 1995). As organizações cooperativas são reconhecidas como sociedades que se fundamentam na ideia de associação voluntária, objetivando a promoção coletiva, com um fim específico para a qual foi criada. Este objetivo comum é que determina o caráter associativista da mesma e motiva a inscrição dos respectivos sócios. Nestas instituições são os sócios que regulam as relações, bem como a distribuição da riqueza produzida de forma responsável e democrática (ROSA, 2010).

Mundialmente, um dos marcos do cooperativismo está ligado, com o surgimento em 1844, na localidade de Rochdale (região inglesa de Manchester), de uma sociedade de ajuda mútua que tinha por objetivo fazer frente aos preços elevados que eram cobrados pelos comerciantes locais. Foram os pioneiros da Rochdale que, baseados na ética e na moral, formularam o estatuto de sua cooperativa tecelã, o qual posteriormente foi difundido pelo mundo como os princípios do cooperativismo (NAMORADO, 1995).

No Brasil, com o advento da Lei $\mathrm{n}^{\circ}$ 5.764/1971 houve a regulamentação do cooperativismo e a instituição de um regime jurídico exclusivo para estas sociedades. Mesmo com a regulação ocorrida apenas na década de 70, segundo a Organização das Cooperativas Brasileiras (OCB), o cooperativismo brasileiro é reconhecido historicamente desde a época da colonização do país. Em 1889 houve a criação da primeira cooperativa em Ouro Preto. Posteriormente, as organizações cooperativas surgiram em outros estados brasileiros como: Pernambuco, Rio de Janeiro e Rio Grande do Sul. Atualmente, as cooperativas brasileiras configuram-se como organizações, na maioria dos casos, de médio e grande porte, com faturamentos elevados e por consequência grandes recolhedores de impostos ao governo e que 
contribuem no desenvolvimento de riquezas de regiões tanto cultural como economicamente (FREITAS; GEHRKE; DREWS, 2011).

Quanto ao seu gerenciamento, as organizações cooperativas são referenciadas como sendo organizações que teriam sistema de gestão e controles democráticos, que objetivariam servir aos sócios que as integram de forma eficiente e eficaz, sempre com propósitos econômicos e sociais, seguindo os valores e princípios do seu sistema. Estes princípios, apresentados no Quadro 1, estão relacionados com valores de honestidade, transparência e responsabilidade, refletindo na estrutura da organização, na orientação das atividades, na atuação dos sócios e na relação com o meio social e ambiental em que a cooperativa atua (SANZ; SALVADOR; CASTEL, 2009).

\section{Quadro 1 - Princípios do cooperativismo}

\begin{tabular}{|l|l|}
\hline Princípio & Explicitação \\
\hline Adesão voluntária e livre & $\begin{array}{l}\text { As cooperativas são organizações voluntárias, abertas a todas as } \\
\text { pessoas sem discriminação política, sexual, social ou racial. }\end{array}$ \\
\hline Gestão democrática & $\begin{array}{l}\text { Os membros das cooperativas participam ativamente na definição } \\
\text { de suas políticas e tomada de decisões. }\end{array}$ \\
\hline Participação econômica dos sócios & $\begin{array}{l}\text { Os membros contribuem equitativamente e controlam } \\
\text { democraticamente o capital de sua cooperativa. Normalmente, os } \\
\text { membros recebem uma compensação limitada sobre o capital } \\
\text { como condição de sua adesão e destinam os excedentes a } \\
\text { determinados propósitos. }\end{array}$ \\
\hline Autonomia e independência & São organizações autônomas, controladas por seus sócios. \\
\hline Educação, formação e informação & $\begin{array}{l}\text { Fornecem educação e treinamento aos sócios, representantes, } \\
\text { administradores e funcionários, para que possam contribuir para o } \\
\text { seu desenvolvimento. }\end{array}$ \\
\hline Cooperação entre cooperativas & $\begin{array}{l}\text { As cooperativas servem mais eficazmente aos seus membros, } \\
\text { quando trabalham em conjunto com outras estruturas locais, } \\
\text { regionais, nacionais e internacionais. }\end{array}$ \\
\hline Interesse pela comunidade & $\begin{array}{l}\text { Através de suas políticas, trabalham para o desenvolvimento } \\
\text { sustentável das comunidades. }\end{array}$ \\
\hline
\end{tabular}

Fonte: Adaptado de International Co-operative Alliance (2016).

O conjunto dos princípios do cooperativismo explicita as ações que as cooperativas devem desenvolver no ambiente onde estejam inseridas. De forma geral, também traça orientações sobre a gestão destas entidades, a qual deve seguir um conjunto articulado de instrumentos que envolvem os sócios, principalmente pela falta de identidade e participação destes nas decisões da organização (SPEAR, 2004). A preservação desses princípios norteadores orienta um trabalho de monitoramento, a separação entre propriedade e controle, a profissionalização da gestão, valorizando também a educação cooperativista e o treinamento como forma de incentivar uma participação mais ativa dos cooperados nas decisões (BIALOSKORSKI NETO, 2012). 
Uma forma de cumprimento dos princípios inerentes ao cooperativismo e de aprimoramento da estrutura administrativa, é o desenvolvimento de mecanismos de governança nas cooperativas, como forma de transmitir maior transparência nos seus atos, aprimorar o relacionamento entre sócios e administração e com outras partes envolvidas (MAS et al., 2008). Um governo mais corporativo neste tipo de organização tem a finalidade de fortalecer o sistema de gestão, controle e administração, tornando-a mais eficiente e democrática, além de facilitar a participação ativa dos sócios no desenvolvimento das políticas e das tomadas de decisões das cooperativas (POYATOS; GÁMEZ; HERNÁNDEZ, 2009).

\section{GOVERNANÇA EM COOPERATIVAS}

O sistema de governança ganhou destaque juntamente com estudos sobre a divisão de controle e gestão nas corporações (JENSEN; MECKLING, 1976; FAMA; JENSEN, 1983; GILLAN, 2006). Mesmo sendo desenvolvidos primeiramente para empresas, os princípios e práticas do sistema de governança também podem ser adotados e permitir benefícios para organizações não empresariais, por meio do alinhamento de interesses em busca de contribuir para o sucesso da organização e para sua longevidade (IBGC, 2014).

No ambiente cooperativo a discussão do sistema de governança pressupõe a compreensão da estrutura de organização das cooperativas. Nestas entidades, os membros têm poder de decisão e controle, segundo o princípio de que o membro é usuário, proprietário e investidor dessa organização. Com frequência não existe separação entre propriedade e gestão ou um gestor profissional contratado com funções de Chieff Executive Officer - CEO (COOK, 2013). Esta arquitetura organizacional difere daquela de empresas de capital ao passo que as cooperativas não apresentam separação entre propriedade e controle, pelo fato de não haver uma estrutura de direitos de propriedade claramente definida, fator este, que resulta em uma relevante estrutura de custos de agenciamento (BIALOSKORSKI NETO; BARROSO; REZENDE, 2012).

Assim como na governança corporativa - reconhecida como "[...] o sistema pelo qual as organizações são dirigidas, monitoradas e incentivadas, envolvendo os relacionamentos entre proprietários, conselho de administração, diretoria e órgãos de controle" (IBGC, 2009, p. 19) - a governança cooperativa apresenta características estruturais básicas que refletem na sua direção e controle: 
a) objetivo: proporcionar bem-estar ao associado com desempenho econômico, se possível;

b) relações de agenciamento: membros participam do conselho de administração e o presidente é o CEO da cooperativa, podendo haver superintendente ou outros diretores sob o CEO;

c) relações com associados: não há obrigatoriedade contratual para que o associado tenha atividades econômicas com a cooperativa. $\mathrm{O}$ associado tem direito a voto e a participar da organização, obrigando-se a observar os pressupostos do estatuto. A responsabilização financeira do associado é igual a sua quantidade de capital, contudo, o presidente e membros do conselho tem a responsabilidade privada com as garantias financeiras da cooperativa;

d) controle residual: não existem direitos de controle residual, ou seja, o conselho de administração formado por associados controla totalmente a cooperativa;

e) processo de voto: os associados votam na escolha do conselho administrativo e conselho fiscal;

f) conselhos: o conselho de administração é composto por número ímpar de membros, geralmente entre 5 e 15 . O conselho fiscal compreende 6 membros, sendo 3 efetivos e 3 suplentes;

g) residual claim: refere-se aos membros que não recebem o seu crédito residual, mas frequentemente este montante é investido novamente nas organizações cooperativas;

h) proprietário: o associado é o proprietário com uma quota-parte;

i) benefícios: as cooperativas tentam oferecer aos associados melhores preços para matérias-primas e insumos. Adicionalmente, alguns serviços são prestados gratuitamente;

j) formação de capital: o capital é formado pelos resultados financeiros das cooperativas e da captação de recursos externos, visto que o valor da quota-parte geralmente é baixo;

k) capital social: não há programa de resgate de capital social. No final do período de associação, o membro poderá reaver seu capital social subscrito, frequentemente, em valores muito abaixo do mercado; 
1) endividamento: a estrutura da dívida é formada por empréstimos bancários privados e governamentais, além de empréstimos cooperativos aos associados (BIALOSKORSKI NETO, 2012).

Referenciada uma estrutura básica de governança cooperativa, observa-se este sistema como balizador dos processos organizacionais dessas entidades, já que envolve práticas de direção e controle, além de buscar pautar a forma de relacionamento entre os membros da administração e demais associados, protegendo os interesses de todos aqueles que a integram (LAMENZA, 2008; FRANCO; RODRIGUES; CAZELA, 2009).

Para consolidar a governança como sistema de gestão, as organizações adotam princípios e definem determinada estrutura que as diferenciam, visando aumentar seu valor e atratividade, facilitar acesso a capital e contribuir para sua efetividade. Normalmente este conjunto de práticas de governança é elaborado por instituições independentes (OLIVEIRA, 2011), não havendo, contudo, um consenso global referente aos princípios que devem ser adotados e como deveriam ser estruturadas as práticas de governança nas organizações.

Entre as empresas de capital, os princípios de governança mais difundidos são: disclosure, fairness, compliance, accountability e ética. Estes princípios viabilizam uma metodologia de sistema focada cada vez mais na comunicação transparente, divulgação de resultados, gestão de riscos, adequada remuneração de executivos e garantia de direitos às partes minoritárias (VERHEZEN; MORSE, 2009).

No âmbito cooperativo há poucos estudos científicos que propõe estruturas de governança especificamente a este tipo de organização, embora apresentem-se estudos que discutam isoladamente a aplicabilidade de determinados elementos - conselho de administração, transparência, prestação de contas, organização sistêmica, participação dos associados - como pilares da governança (FONTES FILHO; MARUCCI; OLIVEIRA, 2008; SIQUEIRA, 2011; BIALOSKORSKI NETO, 2012; BIALOSKORSKI NETO; BARROSO; REZENDE, 2012).

Diante do contexto de representatividade do sistema cooperativo brasileiro, encontrase em discussão um guia que dispõe as melhores práticas de governança aplicadas a esse tipo de organização. A versão preliminar desse material traz recomendações que objetivam a preservação e a otimização do valor da cooperativa, o que contribuiria para sua longevidade e perenidade (IBGC, 2014). Embora haja a expectativa de implementação oficial desse guia, salienta-se que boas práticas de governança cooperativa já são requisitos adotados por 
cooperativas de crédito no país, sendo exigências para a sua manutenção no mercado financeiro (BANCO CENTRAL DO BRASIL, 2008).

Além da contemplação dos princípios e da estrutura de governança nos códigos ou guias de boa governança, podem-se evidenciar estas informações em outros documentos institucionais: códigos de conduta, regimentos internos e estatutos sociais das organizações. Como este estudo propõe-se a identificar as práticas de governança em organizações cooperativas a partir da análise dos estatutos sociais, por serem documentos que fundamentem os processos e relação dessas organizações, no próximo tópico se discute como ocorrem as questões contratuais no âmbito cooperativo.

\section{ARQUITETURA CONTRATUAL COOPERATIVA}

Com a evolução das instituições também evoluíram as formas que parametrizam todas as atividades inerentes a elas. Todas as transações ocorridas nas organizações são regidas por meio de contratos formais amparados em leis ou acordos informais que levam em consideração a reputação e outros mecanismos sociais das partes. Estes contratos representam sua forma de relação entre as partes envolvidas assim como sua regulação interna (ZYLBERSZTAJN, 2005).

O contrato poderia ser "definido como um acordo de vontades que é capaz de gerar direitos e obrigações para partes envolvidas no negócio; vale dizer, é um espaço de autorregulação dos sujeitos privados” (TIMM, 2013, p. 224). Segundo este autor, o contrato abrange não somente as vontades de partes, mas também sofre regulação pela legislação inerente, que busca resguardar os efeitos que podem trazer à sociedade.

No caso particular das cooperativas, estas organizações são regidas e suas atividades estão voltadas para o cumprimento do seu estatuto social, o que as difere das empresas que são formadas por um contrato social para desenvolver suas atividades. Nestes estatutos as cooperativas descrevem, por exemplo, os objetivos sociais à que se propõe, quem pode se associar, direitos, deveres e responsabilidades dos associados e da sua administração.

O estatuto social - documento base da arquitetura contratual das cooperativas - refle os mecanismos de gestão utilizados por estas organizações e elenca informações que dão equilíbrio às relações existentes, principalmente entre administração e associados, buscando resguardar direitos e deveres de ambas as partes, mas acima de tudo, esta forma de contrato estaria a serviço da diminuição dos custos de transação implicados em qualquer processo associativo, formal ou informal (ZYLBERSZTAJN, 2005). 
Nota-se no âmbito cooperativo uma arquitetura do ambiente institucional, por meio de relações contratuais em que este ambiente caracterizado pela doutrina da cooperação, poderá ser, por um lado, uma restrição à otimização de resultados econômicos e lucros, mas por outro lado poderá apresentar resultados sociais relevantes (BIALOSKORSKI NETO, 2012). Contudo, evidenciam-se fragilidades na arquitetura contratual das cooperativas, especialmente por apresentarem direitos de propriedade vagamente definidos, o que acarreta problemas de carona, em que os benefícios da cooperativa acabam por beneficiar também membros não cooperativados que não tem atividades e custos com a organização, mas que se beneficiam dos resultados desta organização (COOK, 1995). Estas fragilidades, especialmente no caso brasileiro, ocorrem devido às organizações cooperativas apresentarem relações contratuais com maior grau de informalidade.

Dado que a arquitetura contratual das cooperativas está baseada formalmente no seu estatuto social, esta instituição formal tem a função de diminuir as incertezas e estabelecer uma base estável para as relações neste ambiente. Neste contexto, as instituições, compreendidas por regras formais e informais e os mecanismos responsáveis pela eficácia desses dois tipos de normas (NORTH, 1994), ditam os processos e relações no âmbito cooperativo, caracterizando-se como as regras do jogo nestas sociedades (NORTH, 1995).

Dessa forma, os contratos sociais de empresas em geral e os estatutos sociais de cooperativas, são documentos nos quais podem estar amparadas as práticas de governança adotas por estas organizações. Já preceituava Berle e Means (1984), que era nos contratos que estavam resguardados os direitos originais dos acionistas, incluindo os direitos de participação e a formação de regras de conduta da administração, exemplos de práticas de governança nas organizações.

\section{PROCEDIMENTOS METODOLÓGICOS}

A pesquisa caracteriza-se como descritiva com evidências qualitativas. O estudo compreendeu a análise de doze estatutos sociais de cooperativas agropecuárias filiadas a Federação das Cooperativas Agropecuárias do Rio Grande do Sul, entidade representativa desta categoria. O critério de utilização dessa amostra se deu em função da acessibilidade aos dados necessários à consecução do estudo.

Para o desenvolvimento do estudo, analisou-se primeiramente o código de boa governança editado pelo IBGC (2009) e o estudo de Bialoskorski Neto (2012). Ambos autores traçam princípios e características da governança que se sugere adequarem-se às cooperativas. 
A partir desta análise inicial foram criados 46 indicadores de governança divididos em 7 categorias, conforme o Quadro 2, os quais caracterizam uma proposta inicial de estrutura de governança para as organizações objeto desta pesquisa.

A estrutura proposta envolve práticas de governança que podem ser identificadas em organizações cooperativas e abrange as ações dos conselhos de administração e fiscal, relacionamento com os sócios e demais questões de gestão que caracterizam uma administração mais transparente, responsável e que objetiva o crescente desenvolvimento da entidade. Os indicadores criados serviram de base para a posterior identificação da utilização de práticas de governança nas organizações cooperativas.

Para a evidenciação da adoção das práticas pelas cooperativas, procedeu-se a consulta documental aos estatutos sociais das cooperativas, buscando identificar a presença de cada indicador proposto, segundo a sua categoria. A partir dessa identificação inicial teceu-se uma análise da utilização de práticas de governança nestas organizações, buscando responder ao questionamento central da pesquisa.

Quadro 2 - Indicadores de governança para cooperativas agropecuárias

\begin{tabular}{|c|c|c|}
\hline Estrutura de Governança & Item & Informações a serem identificadas \\
\hline \multirow{13}{*}{ Conselho de Administração } & 1 & Atribuição \\
\hline & 2 & Composição \\
\hline & 3 & Remuneração \\
\hline & 4 & Qualificação \\
\hline & 5 & Avaliação do conselho \\
\hline & 6 & Disponibilidade de tempo \\
\hline & 7 & Prazo do mandato \\
\hline & 8 & Presidente do conselho \\
\hline & 9 & Educação contínua do conselho \\
\hline & 10 & Novos conselheiros \\
\hline & 11 & Formação de comitês \\
\hline & 12 & Conflitos de interesse \\
\hline & 13 & Confidencialidade \\
\hline \multirow{8}{*}{ Sócios } & 14 & Direito a voto \\
\hline & 15 & Acesso a assembleia geral \\
\hline & 16 & Participação na tomada de decisões \\
\hline & 17 & Política de divisão de sobras e perdas \\
\hline & 18 & Condições para saída de sócios da sociedade \\
\hline & 19 & Prestação de informações \\
\hline & 20 & Relação entre sócios e gestores \\
\hline & 21 & Voto por procuração \\
\hline \multirow{5}{*}{ Auditoria } & 22 & Qualidade e integridade dos relatórios \\
\hline & 23 & Função do auditor interno \\
\hline & 24 & Função do auditor externo \\
\hline & 25 & Recomendações dos auditores \\
\hline & 26 & Contratação e remuneração de auditorias \\
\hline
\end{tabular}




\begin{tabular}{|c|l|l|}
\hline \multirow{4}{*}{ Conselho Fiscal } & 27 & Independência \\
\hline & 28 & Atribuição \\
\cline { 2 - 3 } & 29 & Composição \\
\cline { 2 - 3 } & 30 & Agenda de trabalho \\
\cline { 2 - 3 } & 31 & Relação com sócios e comitês \\
\cline { 2 - 3 } & 32 & Remuneração \\
\cline { 2 - 3 } & 33 & Independência \\
\cline { 2 - 3 } & 34 & Pareceres \\
\cline { 2 - 3 } & 35 & Conflitos de interesse \\
\hline \multirow{5}{*}{ Gestão } & 36 & Indicação de diretores \\
\cline { 2 - 3 } & 37 & Transparência de informações \\
\cline { 2 - 3 } & 38 & Controles internos \\
\cline { 2 - 3 } & 39 & Relacionamento com as partes \\
\cline { 2 - 3 } & 40 & Remuneração dos gestores \\
\cline { 2 - 3 } & 41 & Código conduta/Regimento interno \\
\hline \multirow{4}{*}{ Cumprimento do Código } & 42 & Uso de informação privilegiada \\
\cline { 2 - 3 } & 43 & Políticas de combate a ilícitos \\
\cline { 2 - 3 } & 44 & Política de divulgação de informações \\
\hline \multirow{4}{*}{ Conduta e Conflito de Interesse } & 45 & Melhoria da qualidade das informações \\
\hline & 46 & Melhoria da supervisão do governo da sociedade \\
\hline
\end{tabular}

Fonte: Dados da pesquisa.

Por fim, são elencadas informações excedentes encontradas nos estatutos e julgadas importantes e que não estão relacionadas à estrutura de governança proposta pelos autores IBGC (2009) e o estudo de Bialoskorski Neto (2012). Estes dados trazem contribuições de forma ajustada à pesquisa proposta, devido ao fato de serem considerados úteis para a formulação, futuramente, de uma proposta consolidada de estrutura para governança cooperativa.

\section{ANÁLISE E DISCUSSÃO DOS RESULTADOS}

De um modo geral observa-se que todas cooperativas analisadas apresentam em seu estatuto social algum tipo de ação que caracteriza um governo cooperativo. Na Tabela 1 estão elencadas as ações presentes na estrutura do conselho de administração.

Quanto à estrutura de governança que envolve o conselho de administração, os estatutos apresentam de forma clara e objetiva a forma de sua composição através de processo eleitoral, prazo de governo, atribuições, qual sócio pode habilitar-se à presidência e os critérios para a renovação dos conselheiros após o final de cada mandato. Constatou-se que em apenas um caso a cooperativa prevê ações para reprimir práticas que tragam algum tipo de conflito de interesse relacionado ao conselho de administração e a direção executiva, como por exemplo, recebimento de benefício de associado em troca de algum favor. 
Tabela 1 - Estrutura de governança: conselho de administração

\begin{tabular}{l|l|c}
\hline Estrutura de Governança & Informação Analisada & Média de Utilização nas Cooperativas \\
\hline & Atribuição & $100 \%$ \\
& Composição & $100 \%$ \\
& Remuneração & $100 \%$ \\
& Prazo do mandato & $100 \%$ \\
& Presidente do conselho & $100 \%$ \\
Conselho de Administração & Novos conselheiros & $100 \%$ \\
& Conflitos de interesse & $17 \%$ \\
& Qualificação & - \\
& Avaliação do conselho & - \\
& Disponibilidade de tempo & - \\
& Educação contínua do conselho & - \\
& Formação de comitês & - \\
\hline
\end{tabular}

Fonte: Dados da pesquisa.

Ainda referente ao conselho de administração, em nenhum caso analisado estão presentes requisitos com relação à qualificação que os conselheiros devem possuir para assumir estes cargos, educação continuada que podem participar para qualificar as atividades, avaliação do conselho e disponibilidade de tempo para dedicar-se às atividades da sociedade cooperativa. Quanto à disponibilidade de tempo, apenas são identificadas as quantidades mensais de encontros que devem acontecer com o conselho.

Questões relacionadas à formação de comitês e de assessoramento ao conselho administrativo (por exemplo, auditoria, tecnologia da informação e recursos humanos) que caracterizam boas práticas de governança, também são itens que não são práticas das cooperativas analisadas. Outro fator importante que faz parte da conduta de gestão de qualquer tipo de organização que não está embasado nos estatutos, foi a questão da confidencialidade que deve estar presente em determinadas ações do conselho de administração devido às suas atribuições.

Quanto à estrutura de governo que está direcionada a satisfação dos direitos dos sócios, identificou-se práticas que estão presentes em todas cooperativas do estudo, conforme representado na Tabela 2 . O direito ao voto e a ser votado tanto em processos eleitorais como na tomada de decisões, a livre participação em assembleias gerais ordinárias e extraordinárias, as condições de inclusão e exclusão dos sócios na entidade, o livre acesso às informações da cooperativa e a implementação de políticas de divisão de sobras e perdas dos exercícios, são exemplos de ações do governo. 
Tabela 2 - Estrutura de governança: relação com os sócios

\begin{tabular}{c|l|c}
\hline Estrutura de Governança & Informação Analisada & Média de Utilização nas Cooperativas \\
\hline & Direito a voto & $100 \%$ \\
& Acesso a assembleia geral & $100 \%$ \\
& Participação na tomada de decisões & $100 \%$ \\
Sócios & Política de divisão de sobras e perdas & $100 \%$ \\
& Condições para saída de sócios da & $100 \%$ \\
& sociedade & $100 \%$ \\
& Prestação de informações & $17 \%$ \\
& Voto por procuração & - \\
\hline
\end{tabular}

Fonte: Dados da pesquisa.

Com relação ao acesso às informações, que caracteriza a transparência nas ações executadas, em todos os casos os sócios têm acesso a estas por meio da participação nas assembleias. Outra forma de inteirar-se das atividades cooperativas é através de pedido por escrito de qualquer informação, que deve ser direcionado à administração da entidade. Não há nenhuma política instalada nestas sociedades que trata especificamente de que tipo de documento está livre para consultas dos sócios e da melhoria que se pode desencadear para estas evidenciações.

Ainda quanto ao direito dos sócios, em 17\% das cooperativas analisadas está normatizada no estatuto a questão do voto por procuração. Nestas entidades este tipo de votação está vedado e é informação relevante que poderia dirimir futuros problemas à sociedade em caso de processos eleitorais e tomada de decisões.

Fator considerado relevante em se tratando de boa governança, refere-se às ações para repressão de possíveis conflitos de interesse entre acionistas e direção das organizações. No caso das cooperativas estudadas não se identificou ações claras no sentido de prevenir possíveis divergências que podem ocorrer entre a administração e os sócios. A não identificação dessa característica, reforça os resultados encontrados em estudos anteriores, especialmente aquele desenvolvido por Bialoskorski Neto, Barroso e Rezende (2012).

Referente à estrutura de auditoria, fator indispensável na governança, percebe-se que não há dentre as cooperativas uma prática comum neste sentido, conforme os dados da Tabela 3. Em apenas uma cooperativa está fundamentada no estatuto social a presença da auditoria interna e suas atribuições. 
Tabela 3 - Estrutura de governança: auditoria

\begin{tabular}{c|l|c}
\hline Estrutura de Governança & Informação Analisada & $\begin{array}{c}\text { Média de Utilização nas } \\
\text { Cooperativas }\end{array}$ \\
\hline \multirow{3}{*}{ Auditoria } & Função do auditor externo & $75 \%$ \\
& Contratação e remuneração de auditorias & $75 \%$ \\
& Independência & $67 \%$ \\
& Função do auditor interno & $8 \%$ \\
& Qualidade e integridade dos relatórios & - \\
& Recomendações dos auditores & - \\
\hline
\end{tabular}

Fonte: Dados da pesquisa.

Em contrapartida, em $75 \%$ dos casos está prevista a possibilidade da contratação de auditoria independente externa de acordo com as necessidades tanto do conselho de administração como do conselho fiscal. Mesmo presente a possibilidade da atuação de auditoria interna e externa, em nenhuma entidade está prevista a forma de apreciação dos laudos dos auditores por parte dos associados.

De acordo com a Tabela 4, ações do conselho fiscal foram identificadas em todas cooperativas. A forma de composição do conselho, a frequência de encontros do grupo, sua remuneração e apresentação dos pareceres foram as práticas encontradas na totalidade da amostra. Em 33\% das entidades está presente a exigência de que o conselho fiscal estabeleça uma relação com os associados, especialmente no que no se refere a fiscalização sobre reclamações e denúncias em serviços desempenhados pela sociedade.

Não estão contempladas práticas que referenciam a independência que deve estar presente nos trabalhos do conselho fiscal, prevenindo que ocorra influência de partes interessadas nos pareceres emitidos em determinados casos. Da mesma forma, não há previsão de ações de governança que possam reprimir possíveis conflitos de interesse entre membros do conselho fiscal de demais envolvidos na cooperativa.

Tabela 4 - Estrutura de governança: conselho fiscal

\begin{tabular}{c|l|c}
\hline Estrutura de Governança & Informação Analisada & Média de Utilização nas Cooperativas \\
\hline & Atribuição & $100 \%$ \\
& Composição & $100 \%$ \\
& Agenda de trabalho & $100 \%$ \\
Conselho Fiscal & Remuneração & $100 \%$ \\
& Pareceres & $100 \%$ \\
& Relação com sócios e comitês & $33 \%$ \\
& Independência & - \\
\hline
\end{tabular}

Fonte: Dados da pesquisa. 
Com relação à gestão das cooperativas, são poucos os índices de utilização de práticas que caracterizam a governança, conforme representação da Tabela 5. Quanto à transparência das informações e das ações desencadeadas nas entidades, todas fazem publicações somente através da prestação de contas nas assembleias gerais ordinárias. Não foi identificada nos estatutos nenhuma outra política que promova a publicação com maior frequência ou até mesmo a melhoria dos tipos de informações divulgadas, visto que apenas são discutidos em assembleia anual os relatórios de gestão, o balanço geral, os demonstrativos de sobras e perdas e os pareceres do conselho de administração e da auditoria.

Tabela 5 - Estrutura de governança: gestão

\begin{tabular}{c|l|c}
\hline \multirow{2}{*}{ Estrutura de Governança } & Informação Analisada & $\begin{array}{c}\text { Média de Utilização nas } \\
\text { Cooperativas }\end{array}$ \\
\hline \multirow{3}{*}{ Gestão } & Transparência de informações & $100 \%$ \\
& Código conduta/Regimento interno & $67 \%$ \\
& Indicação de diretores & $42 \%$ \\
& Relacionamento com as partes & $25 \%$ \\
& Controles internos & $8 \%$ \\
& Remuneração dos gestores & - \\
\hline
\end{tabular}

Fonte: Dados da pesquisa.

A responsabilização pela indicação e contratação de diretores executivos externos que venham a contribuir com sua experiência e conhecimento na gestão das cooperativas está presente em $42 \%$ dos estatutos estudados, no entanto, o que não está normatizado é a forma de remuneração destes cargos. Por sua vez, o regimento interno é um instrumento de gestão que baliza as atividades de $67 \%$ das cooperativas. Estes documentos, juntamente com os estatutos sociais servem de base para todas as atividades prestadas pela entidade, tanto para os administradores como para os sócios, funcionários e demais envolvidos nos negócios.

Ainda com relação a estrutura de gestão, identificou-se que apenas $25 \%$ das cooperativas preocuparam-se em descrever no seu estatuto social como deve ocorrer o relacionamento entre a administração e direção executiva com os sócios, colaboradores e entidades externas a sociedade. Nestes casos, deve a administração e direção primar pelo diálogo com seus stakeholders, além de estar aberta para contribuições que podem ser agregadas para gestão das operações e serviços da cooperativa.

Com relação às práticas de governança que envolve a conduta especialmente da administração e direção das cooperativas, não se encontram formas que coíbam o uso de informações privilegiadas que podem beneficiar determinadas partes. Por outro lado, o estatuto social prevê em $42 \%$ dos casos, que haja a criação de métodos de combate a ilícitos 
dentro das sociedades em todas as atividades desempenhadas, não citando especificamente quais métodos devem ser adotados em cada situação.

Como já discutido na estrutura de governança relacionada à gestão, reforça-se a não observação nos estatutos sociais, de políticas que promovam o aperfeiçoamento da divulgação de informações às partes interessadas na entidade. Da mesma forma, não está sintetizado claramente como se dá o aperfeiçoamento de técnicas de governo nas cooperativas.

Outra proposta de análise nos estatutos sociais foi a identificação de práticas de gestão utilizadas pelas cooperativas excedentes àquelas contempladas na relação de indicadores de governança criados, e que caracterizariam uma boa governança nestas entidades. Foram observadas as seguintes ações de governo e práticas de propriedade nas cooperativas analisadas:

a) treinamento dos sócios: todos os sócios ingressantes na entidade estão obrigados a participar de treinamento que contribua para seu conhecimento técnicoprofissional, sobre todas as atividades desenvolvidas pela cooperativa, bem como para compreender sobre os princípios que norteiam o cooperativismo;

b) responsabilização da administração: os administradores não serão pessoalmente responsáveis pelas obrigações que contraírem em nome da sociedade, mas responderão solidariamente pelos prejuízos resultantes de seus atos se agirem com culpa ou dolo;

c) responsabilização dos sócios: os sócios se responsabilizam pelos compromissos assumidos pela cooperativa até o valor do capital social por ele subscrito no momento de sua adesão na sociedade;

d) exclusão do sócio: qualquer sócio está sujeito a exclusão do quadro social no caso de infração ao estatuto social ou qualquer atividade que exerça que venha a prejudicar a cooperativa;

e) fidelidade do sócio: todos sócios estão obrigados a entregar seus produtos e negociar exclusivamente com a cooperativa a qual estão filiados, nas condições de comercialização exercidas pela entidade;

f) direito do sócio: indicar a adesão de um novo sócio;

g) capital social da entidade: representado por quotas-parte integralizadas pelos sócios no momento da adesão à entidade;

h) prestação de contas: compreende exclusivamente a apresentação de relatórios da administração, balanço geral e pareceres de auditores e conselho fiscal; 
i) ações do conselho de administração: necessariamente devem ter aval da assembleia geral para sua implementação.

Salienta-se que as medidas de gestão citadas anteriormente são características comuns a este tipo de cooperativa, as quais têm por finalidade principal atender as necessidades de seus associados sem qualquer objetivo de lucro. Importante destacar que várias ações de governo seguidas nestas instituições estão embasadas no regimento interno de cada uma, informação esta destacada nos estatutos sociais.

\section{CONSIDERAÇÕES FINAIS}

Esta pesquisa teve como o objetivo central identificar a utilização de práticas de governança em cooperativas agropecuárias por meio de informações obtidas nos estatutos sociais destas organizações. Para que se alcançasse este objetivo, foram analisados pressupostos de boa governança indicados por diferentes autores, buscando subsidiar a formulação de uma relação de indicadores que poderiam ser aplicados no governo das cooperativas.

A partir dessa nova estrutura proposta, foi identificada a presença da mesma nos estatutos sociais de um grupo de cooperativas agropecuárias. Observou-se de um modo geral que as cooperativas fazem uso de práticas características de boa governança em suas atividades. Mesmo assim, ainda há muitas ações a serem desenvolvidas, comparando-se com a governança utilizada em empresas de capital. As ações identificadas com maior frequência nos estatutos sociais estão relacionadas com o tratamento dispensado aos sócios, especialmente pelo seu acesso na participação de decisões, na composição e atribuições dos conselhos de administração e fiscal.

A questão da transparência de informações, prática comum de governança, nas cooperativas está ligada apenas com a apresentação de relatórios e demonstrativos em assembleias. Esse fato pode dificultar o acesso a informação das partes interessadas, mesmo que estas tenham acesso se solicitarem por escrito pedido de esclarecimentos à administração. Aperfeiçoamento ou implementação de novas políticas de divulgação de informações não são práticas adotadas, segundo os estatutos.

As práticas que merecem maior aperfeiçoamento são as que tratam da relação e do conflito de interesse entre as partes interessadas. Mesmo sendo organizações que não objetivam o lucro e sim o atendimento das necessidades dos associados, as divergências de interesse estão presentes nas cooperativas e constituem-se em risco para o desenvolvimento e 
imagem da organização. Outro fator que não está presente em todas as cooperativas é a atuação contínua de auditores, tanto internos como externos. A auditoria pode contribuir para a melhor clareza, qualidade e confiabilidade dos processos e relatórios produzidos pela entidade, visto que busca primar pela integridade financeira e pela otimização dos processos de todas as áreas da cooperativa.

O assunto abordado nesta pesquisa ganha maior representatividade com a relevância que estas sociedades representam para as comunidades nas quais estão inseridas e pela competitividade que a prestação de seus serviços traz. Estes fatores, juntamente com os resultados obtidos neste estudo despertam interesse em dar continuidade a pesquisas nesta área com uma amostra mais representativa e com a inclusão de cooperativas de outras áreas de atuação.

Outro fator que pode auxiliar na verificação de uso de práticas de governança em cooperativas é a análise conjunta do estatuto social com o regimento interno, formadores da arquitetura contratual destas organizações, visto que são documentos que se complementam e pela pontuação em vários estatutos analisados das regras de governo presentes nos regimentos. Estas análises são importantes devido ao fato de subsidiarem as cooperativas com informações que as auxiliem no contínuo desenvolvimento de estruturas de governança que venham a evitar dificuldades administrativas e financeiras como as que ocorreram em várias entidades e contribuir com a sua longevidade.

\section{REFERÊNCIAS}

BANCO CENTRAL DO BRASIL. Cooperative governance: guidelines for good practices of financial cooperative governance. Disponível em: <http://bcb.gov.br/pre/microFinancas/coopcar/pdf/cooperative_governance_internet.pdf >. Acesso em: 09 set 2014.

BERLE, A. A.; MEANS, G. C. A moderna sociedade anônima e a propriedade privada. São Paulo: Abril Cultural, 1984.

BIALOSKORSKI NETO, S. Economia e gestão de organizações cooperativas. São Paulo: Atlas, 2012.

BIALOSKORSKI NETO, S.; BARROSO, M. F. G.; REZENDE, A. J. Governança cooperativa e sistemas de controle gerencial: uma abordagem teórica de custos de agência. BBR - Brazilian Business Review, v. 9, n. 2, p. 72-92, 2012.

BORGEN, S. O. Product differentiation and cooperative governance. Journal of SocioEconomics, v. 40, n. 3, p. 327-333, 2011. 
COOK, M. L. The future of U.S. agriculture cooperatives: a neo-institucional approach. American Journal of Agricultural Economics, v. 77, p. 1153-1159, 1995.

The impact of CEO tenure on cooperative governance. Managerial and Decision Economics, v. 34, p. 218-229, 2013.

FAMA, E.; JENSEN, M. Separation of ownership and control. Journal of law and economics, v. 26, n. 2, p. 301-325, jun. 1983.

FONTES FILHO, J. R.; MARUCCI, J. C.; OLIVEIRA, M. J. Governança cooperativa: participação e representatividade em cooperativas de crédito no Brasil. Revista de Contabilidade e Organizações, v. 2, n. 4, p. 107-125, 2008.

FRANCO, D. H.; RODRIGUES, E. A.; CAZELA, M. M. (Org.). Tecnologias e ferramentas de gestão. Campinas: Alínea, 2009.

FRANSI, E. C.; SALLA, Y. M.; VIADIU, F. M. La gestión de las cooperativas agrárias: tipificación de las cooperativas del sector oleícola de Catalunya. Revista de Economía Pública, Social Y Cooperativa, Valencia, n. 57, p. 203-236, abr. 2007.

FREITAS, J. A. P.; GEHRKE, L. S.; DREWS, G. A. Relacionamento do quadro social com a Cotripal: um olhar para a fidelização como diferencial econômico. In: BÜTTENBENDER, P. L. (Org.). Gestão de cooperativas: fundamentos, estudos e práticas. Ijuí: Unijuí, 2011. p. 4375 .

GIAROLA, E. et al. Governança Corporativa e Gestão Eficiente de Cooperativas. In: X SEMEAD - SEMINÁRIOS EM ADMINISTRAÇÃO FEA-USP, 10. 2007, São Paulo. Anais...São Paulo: USP, 2007.

GILLAN, S. L. Recent developments in corporate governance: an overview. Journal of corporate finance, v. 12, p. 381-402, 2006.

INSTITUTO BRASILEIRO DE GOVERNANÇA CORPORATIVA. Código das melhores práticas de governança corporativa. 4. ed. São Paulo: IBGC, 2009.

Guia das melhores práticas de governança para cooperativas. Disponível em: <http://www.www.ibgc.org.br/inter.php?id=19006/guia-das-melhores-pra\%C3\%A2ticas-degovernana\%C3\%A2a-para-cooperativas-passa-por-audia\%EF\%BF\%BD\%C2\%AAnciapa\%EF\%BF\%BD\%C2\%BAblica>. Acesso em: 14 jul 2014.

INTERNATIONAL CO-OPERATIVE ALLIANCE. Statement on the Co-operative Identity. Disponível em: <http://www.ica.coop/coop/principles.html>. Acesso em: 14 jan 2016.

JENSEN, M.; MECKLING, W. Theory oh the firm: managerial behavior, agency ownership structure. Journal of financial economics. v. 3, n. 4, p. 305-360, oct. 1976.

LAMENZA, Ademir. (Org.). Estratégias empresariais: pesquisas e casos brasileiros. São Paulo: Saint Paul, 2008. 
MARTÍ, E. M.; IGUAL, J. F. J. La intercooperación: uma respuesta a las actuales demandas del cooperativismo agrário. Estudios de Economía Aplicada, Valencia, vol. 26, n. 1, p. 7588, mar. 2008.

MARTÍNEZ, J. C. Puntos fuertes y débiles de las cooperativas desde un concepto amplio de gobierno empresarial. Revista de Estudios Cooperativos, Madrid, n. 95, p. 65-93, 2008.

MAS, E. S. et al. La innovación em el gobierno de las cajás rurales españolas: evaluación de su e-gobierno corporativo. Revista de Economía Pública, Social Y Cooperativa, Valencia, n. 60 , p. 155-178, abr. 2008.

NAMORADO, R. Os princípios cooperativos. Coimbra: Fora Do Texto, 1995.

NORTH, Douglass. Custos de transação, instituições e desempenho econômico. Rio de Janeiro: Instituto Liberal, 1994.

Instituciones, cambio institucional y desempeño edonómico. México: Foundo de Cultura Económica, 1995.

OLIVEIRA, D. P. R. Governança corporativa na prática. São Paulo: Atlas, 2011.

PEREIRA, A. C. Contribuição a análise e estruturação das demonstrações financeiras das sociedades cooperativas brasileiras: ensaio de abordagem social. Contabilidade Vista \& Revista, Belo Horizonte, v. 6, n. 1, p. 33-41, 1995.

POYATOS, R. P.; GÁMEZ, M. D. M.; HERNÁNDEZ, J. V. El buen gobierno corporativo em las sociedades cooperativas. Revista de Estudios Cooperativos, Madrid, n. 98, p. 118140, 2009.

ROSA, A. D. D. L. El fomento de las sociedades cooperativas. Revista de Derecho, Piura, v. 11, p. 395-415, 2010.

SANZ, F. J. P.; SALVADOR, L. E.; CASTEL, A. G. Participación, gobierno democrático y resultados cooperativos uma perspectiva de RSE. Revista de Economía Pública, Social Y Cooperativa, Valencia, n. 65, p. 163-190, ago. 2009.

SIQUEIRA, L. C. Conselho fiscal e auditoria em cooperativas agropecuárias: uma análise sobre a adoção de práticas de monitoramento. 2011. 159f. Dissertação (Mestrado em Controladoria e Contabilidade) - Programa de Pós-Graduação em Controladoria e Contabilidade, Universidade de São Paulo, São Paulo, SP, 2011.

SPEAR, R. El gobierno democrático em las organizaciones cooperativas. Revista de Economía Pública, Social Y Cooperativa, Valencia, n. 48, p. 11-30, abr. 2004.

TIMM, L. B. Contratos no direito brasileiro. Direito \& Justiça, Porto Alegre, v. 39, n. 2, p. 224-236, 2013.

VERHEZEN, P.; MORSE, P. Consensus on global governance principles? Journal of International Business Ethics, Beijing, v. 2, n. 1, p. 84-101, 2009. 
ZYLBERSZTAJN, D. Papel dos contratos na coordenação agro-industrial: um olhar além dos mercados. Revista de Economia e Sociologia Rural, Brasília. v. 43, n. 03, p. 385-420, 2005. 